\title{
Traditional Ruler, Environmental Education, Pollution and Rural Communities in Nigeria: Challenges and Prospects
}

By

${ }^{1}$ Ihemeje Godwin, Ph.D., ${ }^{2}$ Okorie Ndukaku\& ${ }^{3}$ Ikpe Emmanuel

\begin{abstract}
The central argument of this paper is premised on the fact that awareness level of environmental management is characterized by inadequate education which has resulted to environmental degradation, deforestation and killing of game reserves particularly among rural dwellers. Given the agrarian nature, subsistence economy and cultural norms of the local people who share common belief system; repose enormous respects on their traditional head as he is referred to as the custodian of the people, community and culture, thus positioning the traditional ruler as veritable instrument for educating the rural populace. The paper heavily relies on the secondary source of data collection and employs historical analysis. This paper therefore examines the role of traditional ruler in sensitising rural communities on environmental pollution in Nigeria, with the view to explicate challenges and underlying prospects.
\end{abstract}

Keywords: Traditional ruler, local government, rural communities, adoption mechanism, environmental education.

\section{Introduction}

The need to develop an ethical relationship between man and his environment is anchored on "attitude revolution" as noted by Eugene Odum's argument in his paper "Environmental Ethical and Attitude Revolution" (Odum 1974:10-15). This is a response to myriads of environmental hazards which are mainly anthropogenic in nature. But the identification of the need to combat environmental problems head-on is gradually being acknowledged among environmentalists (Howel, 2014; Toner et al. 2014; Zelenski\&Nisbet, 2014; Adeola, 2000a, b). The burning question presently is; how and what are the means to which the objective of building a friendly environment between man and his environment can be achieved?

In response to the above question, this paper argues that traditional institution with particular respect paid to the traditional ruler, remains one of the most viable tools for reaching the rural dwellers on the need to achieving an ethical relationship between man and his environment as advocated by Odum.

The pursuit and acquisition of wealth has had a tremendous effect on ecosystem and the environment. And traditional institution is the closest institution to citizens in any society. Traditional ruler otherwise known as a local community leader in certain context can play influential or even decisive roles on how people act towards nature and 
environmental resources. This is particularly true in rural areas. In a pluralistic sense therefore, organising environmental orientation programmes for community leaders (traditional leaders) who will in-turn have contact with the rural dwellers can assist to facilitating the implementation of environmental laws.

In working with such leaders, specific attention will have to be paid to issues of language, literacy level and effective medium of communication. The paper is of the view that since traditional ruler-ship institution is closer to the people in terms of language and accessibility in all ramifications; it could work or serve as a better alternative in combating environmental crises by fostering "attitude revolution."

The structure of this paper is divided into five sessions. The first session is the introduction and second session deals with conceptual clarifications. The third session examines traditional ruler, environmental pollution versus apathy/ignorance; while the fourth delves intochallenging factors influencing traditional ruler in propagating environmental education and fifth deals with the prospects.

\section{Conceptual Clarifications}

Concepts are identified as the most basic tool science has at its disposal (Dinwerth\&Pattberg, 2006:186). Local government, rural dweller and traditional ruler are the concepts in this paper. Thus, this section deals with the discourses of concepts as the foundation of its analysis (Akindele et al, 2012:175; Finnemore\&Sikkink, 1998: 891). Such orientation is informed and compelled by the fact that existential complexities and traditional ruler-ship institutioncannot be isolated from environmental education and rural communities, particularly when thinking and appraising governance in Nigeria. More than that, the nation's governance is confronted with environmental hazards. In other words, a concept to concept understanding will begin with definition and discussion of local government.

\subsection{Local Government}

Enormous definitions and literature abound on the concept of 'local government' (Adamolekun, 1983; Aransi\&Ihemeje, 2012; Whalen, 1976, Olowu, 1983). At the international sphere, the United Nations Office for Public Administration defines local government in this direction:

a political subdivision of a nation or (in a federal system) State, which is constituted by law and has substantial control of local affairs including the powers to impose taxes or to execute labour for prescribed purposes. The governing body of such an entity is elected ...(Adamolekun, 1983)

Local government can also be described along these lines:

A given territory and population, an institutional structure for legislative, executive or administrative purposes; a separate legal identity, a range of powers and separate legal identity, a range of powers and functions authorised by delegation from the appropriate central or intermediate legislature, and within the ambit of such delegation, autonomy including fiscal autonomy(Whalen, 1976).

It is germane to succinctly articulate in our discourse the all-embracing definition posited by the federal government of Nigeria when it instituted the 1976 local government reform. In its document, local government is defined as: 
Government at Local level exercised through representative councils established by law to execute specific powers within defined areas. These powers should give the councils substantial control over local affairs as well as the staff and institutional and financial powers to initiate and direct the provision of services and to determine and implement projects so as to complement the activities of the state and federal government in their areas, and to ensure, through devolution of functions to these councils and through the active participation of the people and their traditional institutions, that local initiative and response to local needs and conditions are maximised (Guidelines for Local Government Reform, 1976:1).

In accordance with the provision of the above, it is clear that the 1976 local government reform at the very first time captured what seem to recognise the local government as the ideal third tier of the government, saddling it with requisite place in the constitution of 1979 and 1999. It also connects the role of traditional rulers to the functioning of local government. Emphasis is paid to the specific provision of infrastructural and social amenities, aside the political functions performed at the local government level.

In the same vein, Olowu (1983) captures the definition within two strands - 'local government' and 'administration.' While drawing comparison between the two, Olowu perceives of local government as a collective power and authority vested on a particular group of representatives whose major task centres on designing policies and programmes that addresses the demands of the people and provide for their good life, that is, healthy living. The second strand deals with the smooth running of grassroots, the translation of policies and programmes into concrete reality, together with the rendering of advice falls within the purview of duties of the administrative arm of local government.

Local governments across the different parts of the world are created to perform two broad functions: political and socio-economic. They are to promote and entrench democratic ethos at grassroots, and provide socio-economic services (i.e. service delivery) to the people, particularly in the area of creating an enabling environment.

In essence, our caveat is premised on the fact that local government council if not properly integrating the rural communities in her development initiatives and implementation, then it may become difficult to disseminate awareness strategies to combating pollution.

\subsection{Rural Communities}

Different concepts can be adopted to define 'rural'. The OECD has a convenient benchmark based on population density:

aregion is rural if more than half the people there live in communities with a

population density of fewer than 150 persons per square kilometre (latter, 2006: 3)

According to Official U.S. Census Bureau's definition, rural areas (communities) comprise open county and settlements with fewer than 2,500 residents. Again, rural areas consist of all territory located outside urbanized areas and urban clusters (USDA, 2011). Olaoye (1987) observed that, the concept of rurality is dependent upon its relationship with urbanity for its dependent upon its relationship with urbanity for its meaning. Thus, a community that is not rural is by definition urban. Yahaya (2009) states that 75 to $80 \%$ of people in developing countries live in the rural areas and need positive, relevant and prompt attention in their daily living. For example, the rural roads are not tarred; gutters are not dug to have good drainage and therefore predisposed to erosion, while trees are fell without complying to environmental laws. 
A report on older rural people indicates that "access to information and advice is a key resource for local people in maintaining active and independent lives" (Abissat, 2008:3). Access to information regarding environmental crises and associated climatic changes in their communities should become more pressing since majority of rural inhabitants depend on it for source of livelihood-farming. And as such, access to information is critical to sensitising the people about what they should know concerning their welfare benefits and sources of support to overcoming social exclusion.

\subsection{Traditional Ruler}

Establishing a better understanding of the term 'traditional ruler' becomes very imperative, considering the fact that it has given rise to a number of misinterpretation and misconceptions. The term traditional ruler is derived from tradition. In a bid to clear any form of ambiguity or even scepticism, Fleischacker (1994:45) defines tradition as "a set of customs passed down over the generations, with a set beliefs and values endorsing those customs." In its political sense therefore, a traditional ruler may be referred to as: the traditional head of an ethnic group or clan who is the holder of the highest primary executive authority in an indigenous polity or who has been appointed to the positioning accordance with the customs and tradition of the area concerned by instrument or order of the state government and whose title is recognised as traditional ruler title holder by the government of the State (Ola and Tonwe 2009: 174).

According to Bello-Imam (2007:169), three sources of political authority are easily discernible in modern states in the traditional ruler:

The first source is traditional authority which is essentially the right to rule resulting from the continuous exercise of political power. Hereditary rulership which is manifest in traditional rulership in Nigeria fits into this classification. The second, a charismatic authority which results from exceptional characteristics of the political leader. Examples of Charismatic leadership in contemporary Nigeria are provided by late Dr NnamdiAqikwe, Late Chief ObafemiAwolowo, late AlhajiAminu Kano and AlhajiAbubakirRimi, as well as Dr Achebe, Igwe of Onitsha. The third, it is a legal bureaucratic or legal rational authority, which emanates from the political office the individual holds but not from the individual who bolds the office.

For analytical convenience and from the foregoing, a traditional ruler is seen as the custodian of the people, culture, tradition, religion, philosophies which is hitherto translated to the role of educating the rural populace, creation of awareness on new innovations and facilitating follow-up. For instance, prior to independence of Nigeria, under the Macpherson Constitution of 1951 there was a provision for the traditional rulers to represent in the selection process of members in the House of Chiefs, as well as indirectly through their influence over the composition of the regional Houses of Assembly (Nworah, 2011). In this regard, it is apparent that the office and person of traditional ruler isinevitable for being saddled with crucial responsibility; mainly because of his nearness to the people, knowing and understanding their felt-needs, and able to articulate way forward in a manner that would be appreciably understood and accepted. Again, he knows the people and is endowed with instruments of discovering their potentials. The traditional rulers usually reside in communities that are not usually urban in nature, known as rural communities. 


\section{Traditional Ruler: Enronmental Pollution Versus Apathy/Ignorance}

The traditional ruler in the discharge of his duties in combating environmental crises is faced with enormous problems which include pollution and apathy.

\subsection{Pollution}

Pollution is the introduction of contaminants into a natural environment that causes instability, disorder, harm or discomfort to the ecosystem i.e. physical systems or living organisms (Merriam-Webster, 2010). Pollution can take the form of chemical substances or energy, such as noise, heat, or light. Pollutants, the elements of pollution, can be foreign substances or energies, or naturally occurring; when naturally occurring, they are considered contaminants when they exceed natural levels. Pollution is often classed as point source or nonpoint source pollution.

\subsection{Types Of Pollution}

The major types of pollution identified in this work are listed below along with the particular pollutants relevant to each of them:

- Air pollution is the release of chemicals and particulates into the atmosphere. Common gaseous air pollutants include carbon monoxide, sulphur dioxide, chlorofluorocarbons (CFCs) and nitrogen oxides produced by industry and motor vehicles. Photochemical ozone and smog are created as nitrogen oxides and hydrocarbons react to sunlight. Particulate matter or fine dust is characterized by their micrometres size $\mathrm{PM}_{10}$ to $\mathrm{PM}_{2.5}$.

- Light pollution, includes light trespass, over-illumination and astronomical interference.

- Noise pollution encompasses roadway noise, aircraft noise, industrial noise as well as high intensity sonar.

- Soil contamination occurs when chemicals are released by spill or underground leakage. Among the most significant soil contaminants are hydrocarbons, heavy metals, herbicides, pesticides and chlorinated hydrocarbons (U.S. EPA, 2010).

- Radioactive contamination, resulting from 20th century activities in atomic physics, such as nuclear power generation and nuclear weapons research, manufacture and deployment.

- $\quad$ Thermal pollution is a temperature change in natural water bodies caused by human influence, such as use of water as coolant in a power plant.

- Visual pollution which can refer to the presence of overhead power lines, motorway billboards, scarred landforms (as from strip mining), open storage of trash or municipal solid waste.

- Water pollution, by the release of waste products and contaminants into surface runoff into river drainage systems, leaching into groundwater, liquid spills, wastewater discharges, and eutrophication and littering. 


\subsection{Pollutants}

A pollutant is a waste material that pollutes air, water or soil, and is the cause of pollution

Three factors determine the severity of a pollutant: its chemical nature, the concentration and the persistence.

\subsection{Sources And Causes}

Air pollution comes from both natural and man-made sources. Man-made pollutants are generated from combustion, construction, mining and agriculture; they contribute greatly to air pollution (United Nations, 1972). Motor vehicle emissions are one of the leading causes of air pollution (EPR, 2001; AU, 2006). Principal stationary pollution sources include chemical plants, coal-fired power plants, oil refineries (Beychok, 1967), petrochemical plants, nuclear waste disposal activity, incinerators, large livestock farms (dairy cows, pigs, poultry, etc.), PVC factories, metals production factories, plastics factories, and other heavy industry. Agricultural air pollution comes from contemporary practices which include clearing and burning of bush/natural vegetation as well as spraying of pesticides and herbicides (Carson, 1962).

Some of the common soil contaminants are chlorinated hydrocarbons (CFH), heavy metals (such as chromium, cadmium--found in rechargeable batteries, and lead--found in lead paint, aviation fuel and still in some countries, gasoline), zinc, arsenic and benzene.

\subsection{Apathy/ Ignorance}

There is no doubt that environmental education and awareness has helped and will continue to help in shaping people's psyche and open their eyes to environmental issues of the day. But the most devastating and encompassing problem related to the abuse of environmental resources today is apathy and ignorance.

Apathy and ignorance exist at all levels of the society, ranging from everyday consumers who fail to recycle, to industrialized nations that are either unaware of the environmental problems (urban air pollution, soil erosion, species extinction, global warming, and so on) or not sufficiently concerned about the state of affairs to address these issues.

Robbins maintains that the lack of consideration and apathy about environmental problems arises from disconnect that has developed between humans and the land on which we live (Robbins, 2003:1). Thus, apathy and ignorance exist when human beings only see nature as not having value in itself, to serving man's needs. With such, there exist a gap between man and nature. Robbins goes further to assert that the end result of this disconnect is that we now have societies, especially in the industrialized world, who do not understand the importance of a healthy environment and its relation to the overall welfare and health of humans. Despite effort to do contrary, industrialized nations are still mostly ignorant and apathetic in terms of environmental awareness. Appreciation for the natural beauty of the earth appears to be non-existent a times (Robbins, 2003:1).

Some of the causes of apathy and ignorance are lack of access to resources as well as inadequate education. Many people are ignorant because they choose to remain ignorant. 
And to be ignorant is trying to refuse to engage in the discussion and the implementation of change.

\section{Challenges Confronted by the Traditional Ruler In Propagating Environmental Education}

The traditional ruler is usually confronted with plethora of challenges while attempting to effectively carry out environmental education programmes within his community. Some of these challenges include poverty, high population, illiteracy and nature of rural community (Olojede, et al. 2013; Kolawole, 2012; National Bureau Statistics, 2007; Issa, 1998; World Bank, 1990). These challenges give a vivid picture of Nigerian rural communitieswith a step-by-step exposition.

First, poverty is a rural community construct (World Bank, 1990; Fields, 2000; UNDP, 2006). Informed by this fact, the rural communities in Nigeria therefore are vulnerable to all kinds of environmental conundrums. Further, "poverty is the deprivation side of human development - the denial of basic choices and opportunities to lead a long, healthy, creative and free life, to enjoy a decent standard of living; and to participate in the life of the community including political freedom and cultural choices" (UNDP, 2006:8). Again, poverty can be seen as a process whereby its essential root causes are embedded in inequality, insecurity, vulnerability and discrimination (World Bank, 2006). We may therefore infer that rural community poverty relates to deficit in infrastructure, security provision, environmental sanitation, and "economic incomes fall drastically below the community average" (World Bank, 2000). Attacking poverty at that level means that there is availability of equal opportunities, decent work, economic and social security, non-discrimination, empowerment and making social and economic institutions more fair and accountable (World Bank, 2006). This is considered as "standard setting" because most developing countries, especially Nigeria might find it difficult to achieve due to weak policy implementation.

Second, Nigeria is the most populous black nation of about 140 million in 2007 (National Population Census, 2007); it is estimated now to be 158.4 million out which rural population is estimated 50,739 while 143 million are of rural poor (World Bank. 2010).

Third, note that Nigeria houses majority of her populace in the rural communities; hence accounting for high illiteracy level in the country. They lack access to education in terms of reading, writing and numeracy, and functional literacy which put them at a disadvantaged group with respect to environment education and awareness. Since there is high illiteracy rate, "the rural populace/ dwellers suffer from acute low productivity, social and economic retrogression due to ignorance which is a direct consequence of their inadequate information provided to them" (Issa, 1998: 132). This therefore suggests that a literate rural dweller would have acquired basic knowledge and skills, usually those pertaining to environmental education; and is able to apply them effectively. Success of environmental education programme largely depends on quality and quantity of literates in a community.

Fourth, the nature of the rural community to a large extent influence environment cum economic activities. For example, if a rural community is economically driven, it ensures 
that food is provided; rural industries are sustained through the provisions of raw materials, and providing income (Olojede, et al. 2013: 390).

Other challenges are inadequate monitoring by environmental experts on policy action as regard pollution; insufficient manpower; lack of compliance on the path of rural dwellers to consistently information into applicability; for example, bush burning and felling down of trees (deforestation), over politicisation of project implementation on the path of local government council.

\section{Prospects: Traditional Ruler as a Change Agent FOR Accelerating Environmental Education in Nigeria}

This is the concluding session of this paper where so much emphasis is paid to adoption strategies and works of Singh \& Mishra (2008), Rogers (1983). It is believed that for an effective environmental education to be carried out in a rural community; with respect to pollution, the traditional ruler is expected to be effectively involved, hence his role as a change agent. Note that, just like in other developing countries, a large proportion of the Nigerian populace resides in the rural areas (communities) where most people are largely illiterate and depend on farming for their livelihoods (Kolawole, 2012: 220). Most of these farming activities exhibit one form of pollution or the other, which of course, are not unfamiliar to the indigenous leader, the traditional ruler.

Fundamentally, the issue of adoption mechanism needs to be taken seriously because quite a huge number of the rural populace do not easily accept new changes and/or innovations. By adoption, we refer to the formal act by which the form and content of a proposed treaty are established. Treaty negotiation within an international organisation like the United Nations are usually adopted by a resolution of a representative organ of the organisation whose membership more or less corresponds to the potential participation in the treaty in question (Oxford Dictionary, 1990; United Nations' Treaty Collection, 1999).

Adoption refers to a decision to make full use of a new idea as the best course of action available (Singh \& Mishra, 2008:3). Explaining further, there may be the need to either accept or reject a particular innovation by a rural community; if it is accepted then it is adopted, but if it is rejected it is not adopted. Rejection means the decision not to adopt an innovation and therefore cease to use an innovation after adopting earlier, a process known as "discontinuance" (Singh \& Mishra, 2008: 2). Two types of discontinuance exist; replacement and disenchantment (Singh, 2008: 2). In this context, adoption is not unconnected to its process, stages, categories and change agent (Singh, 2008; Rogers, 1983). Adoption mechanism entails network of activities where experimentation, selection and dissemination of innovative ideas take place.

Adoption process is the mental process through which an individual passes from first knowledge of an innovation to a decision to adopt or reject and to later confirmation of this decision (Singh \& Mishra, 2008: 2). There are five stages of adoption process and five adopter categories (Rogers, 1983). The five stages of adoption are awareness, interest, evaluation, trial and adoption; while the adopter categories include innovators, early adopters, early majority, late majority and laggards (Rogers, 1983). 
A change agent exists to ensuring a balance and effective co-ordination of network of activities that transpire between the stages of adoption process and adopter categories. A change agent has the potential to direct activities involved in the relationship between the stages of adoption process and the adopter categories. In this regard therefore, a change is defined as an individual who influences clients' innovation decisions in a direction deemed desirable by a change agency (Singh \& Mishra, 2008: 4). Examples of change agents in a rural community are traditional rulers, teachers, political scientists, consultants, local government experts, community development experts, development workers, environmentalists, public health workers, agricultural extension workers, development workers and sales representatives.

The question of roles performed by the change agent is pertinent to this discourse. Response to the question in a scholarly documentation states that:

a change agent performs two major roles of diffusion of innovation: one, provides linkage between change agency and client system, he passes the innovation(s) from change agency to ultimate users; two, identifies clients' needs and obtain feedback about change programme and feed it to change agency (Singh \& Mishra, 2008: 4).

In view of the above, the de facto role of change agent within the purview of environmental pollution education is assumed by the traditional ruler. To expedite innovative ideas of ameliorating environmental pollution in his community, it is expected that firstly, the traditional ruler should be very conversant and knowledgeable about environmental issues in his community as this would help to identify areas where environmental education will anchor on.

Secondly, there is need to increase the knowledge base capacity of the rural dwellers through periodic meetings, seminars and other related programmes geared towards enhancing an environment-friendly community. Such meetings should be engineered by the traditional ruler and to take place at the palace, community hall, and even at market squares occasionally.

Thirdly, "seeing they say is believing", the people need to be provided with incinerators, dust bins, boots and other kits to help combat the environmental menace like that of pollution and erosion. This aspect need to be facilitated by the traditional ruler. Thus, the traditional ruler occupies an intermediary role between his subjects and environment, also doubles as the link between the local government council and environmentalists in championing sound environmental education, of which he is expected to live up to the honour and respect bestowed on him by ensuring that environmental needs assessment gets desired advocacy and results.

Fourthly, not every adoption mechanism works or even survives the test of time. This is true because the introduction of new way of doing things can either be accepted or rejected. Once accepted, it can be adopted but if rejected, it becomes an impracticable and forgotten endeavour. For instance, the idea of afforestation when adopted in a given rural community should ensure that trees are planted periodically, but; wisely planted when and where necessary. Such a noble initiative would see the light of the day if the following requirements are met:

i. Apart from being the change agent, the traditional ruler can take the leading role as an early adopter to demonstrate a particular innovation with respect to environmental pollution education; 
ii. House-to-house, market-to-market, religious places of worship sensitisation and awareness on afforestation as against deforestation which often result into environmental and health pollution;

iii. Frequent announcement through radio jingles and television programmes;

iv. Seasonal monitoring; and

v. Enlightening primary and secondary pupils on the need to have a healthy environment through early morning and closing period announcements on the assembly ground (or hall, as the case may be).

\section{References}

Abissat, M.K.(2008).Taking ICT to rural people in Ghana [Online]

Available: http://www.ginks.org/com.pages/Get.Bitz from file (Accessed 20/01/2016)

Adamolekun, L. (1983). Public administration: A Nigerian and competitive

perspective. England: Longman Group Limited.

Adeola, F. O. (2000a). Endangered community, enduring people, toxic contamination,

health and adaptive responses in local context. Environment and Behaviour,

32.2: 209-249.

Adeola, F. O. (2000b). Cross-national environmental hazards, health injustice and human

rights issues: A review of avoidance in the developing world. American Behavioural Scientists Vol. 43 (4): 668 706

Adeola, F. O. (1994). Environmental hazards, health and racial inequality in hazardous

waste distribution. Environment \& Behaviour, 26 No 1:99-126

Akindele, S.T. Adeyemi, O.O. \&Aluko, O.A. (2012). Democracy, governance, legislative

challenges and impediments in Nigeria, 1999-2011. Journal of Politics and

Law, Vol. 5, No. 2.

AU (2006).State of the environment issue: Air quality[Online]

Available:http:/ / www. environment. gov. au/soe/ 2006/ publications/ drs/ atmosphere/ issue/ 188/ index.html (Access 24/01/2016)

Bello-Imam, I.O. (2007). The local government system in Nigeria. Ibadan: College Press

\&Publishers Limited.

Beychok, Milton R. (1967). Aqueous W astes from Petroleum and Petrochemical Plants (1st \& Sons. LCCN 67019834.

ed.). John Wiley

Carson, R. (1962).Silent Spring. United States: Houghton Miffin.

Dinwerth, K. \&Pattberg, P. (2006).Global governance as a perspective on world politics. Global Governance 12, pp.186.

EPR (2001). Environmental performance report 2001 [Online] Available:

http:/ / www.tc. gc. ca/ programs/ environment/ ems/ epr2001/ awareness.html(Accessed 20/01/2016)

Fields, G. S. (2000). The dynamics of poverty, inequality and economic wellbeing:

African economic growth in comparative perspective. Journal of African Economies, Vol. 9: 45-78.

Finnemore, M.\&Sikkink, K. (1998). International norm dynamics and

political change. International Organisation 52, 4, Autumn, pp.891.

Fleischacker, S. (1994). The ethics of culture. Ithaca: Cornell University Press.

Guidelines for Local Government Reform 1976 in Nigeria. Kaduna: Government Printer.

Halma(2011).Local government, traditional rulers and socio-economic development in

the northern states. Gamji Members Association (GAMA) Website. (Accessed 19/01/2016).

Issa, A. O. (1998). The information needs of rural dwellers in Kwara State.

In Tijani, A. et al. (eds), Issues in Information provision: Nigerian perspectives.

Zaria: Naliss.

Kolawole, O. D. (20120. Is literacy key to community development? Analyzing two groups

of adults' involvement in development projects in Northern Nigeria. PULA: Botswana Journal of African Studies. Vol. 26. No 2 Issue \#47, pp. 220. 
Latter, J. (2006).Cultural development in rural and remote areas in review of

Canada Council Support [Online] Available:http://www.canada council.ca/publicationsdresearch//b/27234975508906250.html (Accessed 20/09/2015).

Odum, E.P. (1974). Environmental ethicsand the attitude revolution. In Blackstone,

W.T.(ed),Philosophy and Environmental Crisis. Athens: University of Georgia Press.

Ola, R.O.F. \&Tonwe, D.A. (2009).Local administration and local government in Nigeria. Lagos: Amitop Books Limited.

Olawoye, J. E. (1987). Degree of rurality: questioning the empirical existence of the typical village. The Rural Sociologist, Vol. 4 No. 4.

Olojede, A. A., Adekunle, A. A. \& Samuel, E. A. (2013). Analysis of rural literacy as a

panacea for socio-economic development of Nigeria. International Journal of Sociology and Anthropology. Vol. 5 (9), pp. 390

Olowu, D. (1983). Local government in Nigeria: Overview and Prospects.Paper presented at national conference on local government as vehicle for national development, Kaduna.

Marriam-webster.com (2001). Pollution - definition from the Merriam-Webster Online Dictionary. [Online] Available:http:/ / www. merriam-webster. com/dictionary/

pollution merriam-webster.com. (Accessed 19/01/2016)

National Bureau of Statistics (2007).Women and men in Nigeria.Vol. 1.

Abuja: Federal Government of Nigeria.

Nworah, M.(2011).The role of traditional rulers in an emerging democratic Nigeria.

Codewit News.

Robbins, K. (2003). Environmental awareness: overcoming ignorance and apathy by getting people 'outside'

Available: http://www.macalester.edu/environmentalstudies/macenreview/environmentalawareness.pdf (Accessed 27/01/2016).

Rogers, E. M. (1983). Diffusion of innovations. New York: The Free Press.

Singh, B. B. \& Mishra, O. P. (2008). Diffusion and adoption of agricultural

innovations. Agricultural Extension Education Programme.Pantnagar. Pp.: 3-4.

The Concise Oxford Dictionary of Current English 1950. Oxford: Clarion Press.

United States Department of Agriculture (2007).Measuring rurality: What is rural?

Economic Research Service, United States of America.

United Treaty Collection (1999).Treaty reference guide. Online [Available]:

http://intreaty.un.org/English/guide.org(Accessed 26/01/2016)

U.S. EPA (2010).Concerns about MTBE [Online]

Available:http://www.epa.gov/mtbe/water.htm\#concerns(Accessed 26/01/2016)

United Nations (1972).Declaration of the United Nations Conference on the human environment.New York: United Nations Publication.

UNDP (2006). What is poverty? Concepts and measures. Brazil: The United

Nations Development Programme.Pp.8.

Whalen, H. (1976). Ideology, democracy and foundation of local self-government.

In L.D. Feldmann\& M.D. Goldrick (eds),Politics and Government in Urban Canada Selected Readings. Toronto: Methuen.

World Bank (2006). World development report 2006: Equality and development.

[Online] Available: http:go.worldbamk.org/UWYLBRACO (Accessed 26/01/2016).

World Bank (2000).World development report. Washington, DC: World Bank.

World Bank (1990). World development report 1990: Poverty. Washington, DC: World Bank.

Yahya, I.H. (2009). Information services for rural community development in

Nigeria. Kano: Department of Library and Information Science, Bayero University.

EPR (2001).Environmental performance report 2001.[Online] Available:

http:/ / www.tc. gc. ca/ programs/ environment/ ems/ epr2001/ awareness.html (Accessed 20/01/2016) 
